\title{
Analysis of Risk Factors of Bladder Neck Contracture Following Transurethral Surgery of Prostate
}

\section{Yi Zhong Chen}

Mackay Memorial Hospital

Wun-Rong Lin

Mackay Memorial Hospital

\section{Yung-Chiong Chow}

Mackay Memorial Hospital

Wei-Kung Tsai

Mackay Memorial Hospital

Allen W. Chiu

Mackay Memorial Hospital

Marcelo Chen ( $D$ mchen4270@yahoo.com )

Mackay Memorial Hospital

\section{Research Article}

Keywords: Transurethral resection of prostate, Bladder neck contracture, Benign prostate hypertrophy, Thulium enucleation/vaporesection/vapoenucleation of prostate

Posted Date: January 13th, 2021

DOl: https://doi.org/10.21203/rs.3.rs-141632/v1

License: (c) (i) This work is licensed under a Creative Commons Attribution 4.0 International License. Read Full License

Version of Record: A version of this preprint was published at BMC Urology on April 11th, 2021. See the published version at https://doi.org/10.1186/s12894-021-00831-6. 


\section{Abstract}

Backgrounds: The aim of the present study was to investigate the preoperative parameters associated with bladder neck contracture (BNC) after transurethral resection of the prostate (TURP) or Thulium vaporesection, vapoenucleation or enucleation of the prostate (ThuP) and to compare the incidence of BNC after TURP and ThuP.

Methods: Between March 2008 and March 2020, 2,363 patients received TURP and 1,656 patients received ThuP at Mackay Memorial Hospital. A total of 62 patients developed BNC. These BNC patients were age-and operation-matched to 124 randomly sampled TURP/ThuP controls without BNC.

Results: Multivariate analysis showed that when compared with patients without BNC, those with BNC had smaller prostates $(43.0 \pm 18.95 \mathrm{ml}$ vs $57.2 \pm 19.84 \mathrm{ml}, \mathrm{p}<0.001)$, lower resection weight $(11.64 \pm 11.75 \mathrm{~g}$ vs $16.67 \pm 12.84 \mathrm{~g}, \mathrm{p}=0.001)$, shorter operative times ( $43.0 \pm 30.9 \mathrm{~min}$ vs $57.2 \pm 34.5, \mathrm{p}<0.001)$, and slower resection speed $(0.124 \pm 0.081 \mathrm{~g} / \mathrm{min}$ vs $0.151 \pm 0.952 \mathrm{~g} / \mathrm{min}, \mathrm{p}=0.041)$. A greater proportion of $B N C$ patients had history of cerebrovascular accidents $(11 / 62 \mathrm{vs} 7 / 124, p=0.009)$, coronary artery disease( $14 / 48$ vs $16 / 108, p=0.03)$, chronic kidney disease (14/62 vs $11 / 124, p=0.01)$, and two or more comorbidities $(29 / 62$ vs $27 / 124, p=0.001)$. A ROC curve predicted that a prostate volume $<42.9 \mathrm{~cm} 3$ was associated with a notably higher rate of BNC.

Conclusion: This study demonstrated that incidence of BNC was the same in TURP and ThuP and low prostate volume, low resection speed and $\geq 2$ comorbidities were positively correlated with the development of BNC after TURP or ThuP.

\section{Introduction}

Benign prostate hyperplasia (BPH) is a common problem among older males. As life expectancy increases, BPH has become a common problem. ${ }^{1} \mathrm{BPH}$ with lower urinary tract symptoms has a notable impact on daily life and can lead to severe genitourinary problems. When surgically indicated, bipolar transurethral resection of prostate (TURP) and thulium vaporesection/vapoenucleation/enucleation of the prostate (ThuP), which are the major endoscopic surgery options, are typically performed, and they have been shown to have favorable outcomes.

Improvement in surgical instruments and technology have resulted in decreased intra-operative and postoperative complications. Bleeding is the most commonly observed intra-operative complication, while dysuria is a bothersome post-operative complication. ${ }^{2,3}$ Post-operative dysuria can often be caused by urethra stricture or bladder neck contracture (BNC). The incidence of BNC in the medical literature has been reported to range from 2.2 to $9.8 \% .{ }^{4}$

The underlying mechanism of BNC is not currently well understood. ${ }^{5}$ Many risk factors have been associated with BNC, such as untreated preoperative urinary tract infection, small prostate volume, unsuitable resectoscope diameter, long operative time, history of prostatitis and postoperative Foley 
insertion. ${ }^{5-7}$ The aim of the current study was to investigate the preoperative parameters associated with the occurrence of BNC after TURP or ThuP, and the difference in BNC incidence rates between TURP and ThuP.

\section{Methods}

We retrospectively reviewed the medical records of patients who underwent either TURP or ThuP at Mackay Memorial Hospital between March 2008 and March 2020. A total of 2,363 patients underwent TURP and 1,656 patients ThuP. Patients with primary bladder neck stenosis, active infection before surgery, history of previous endoscopic surgery of the urinary tract, or incomplete data were excluded from this study. A total of 66 patients found to have BNC after the procedure and a total of 3953 patients didn't have BNC after the procedure. Four were excluded due to lack of PSA data, and therefore a total of 64 patients were included in the study. None of these patients had peri-operative and post-operative infection, such as urinary tract infection, epididymitis, or orchitis. BNC occurred after TURP in 35 patients and after ThuP in 27 patients. They all subsequently received bladder neck incision at a later date. BNC was suspected if patients complained of progressive dysuria or gradually decreasing maximal urinary flow (less than $10 \mathrm{~mL} / \mathrm{s}$ in the urodynamic study). Definite diagnosis was made by cystoscopy. Upon confirmation of the diagnosis of BNC, bladder neck incision was performed using bipolar instruments (energy set at $160 \mathrm{~J}$ for cutting and $80 \mathrm{~J}$ for coagulation). After the procedure, there was no recurrence of BNC. Due to low incidence rate $(1.6 \%, 66 / 4019)$ of BNC, we designed a 1:2 case control cohort. These 62 BNC patients (BNC group, 35 TURP and 27 ThuP) were age-and operation-matched to 124 randomly sampled controls without BNC (NBNC group, 70 TURP and 54 ThuP). There was no statistically significance in age and operation between BNC and NBNC group. (Table 1)

The standard procedures for TURP and ThuP was: 1) urethral sounding from 16 French $(\mathrm{Fr})$ to $32 \mathrm{Fr}$. 2) Insertion of a $24 \mathrm{Fr}$ resectoscope in a $26 \mathrm{Fr}$ sheath. 3) Resection of the prostate piece by piece using bipolar instruments (energy set at $160 \mathrm{~J}$ for cutting and $80 \mathrm{~J}$ for coagulation) or vaporesection or enucleation of the prostatic adenoma with a 120W-Thulium laser (Vela XL or RevoLix 120, energy set at 20-40Watt for enucleation and 60-80Watt for resection). 4) Resected tissue was then morcellatedor evacuated. 5) Final hemostasis was achieved with bipolar instruments (160J for cutting and $80 \mathrm{~J}$ for coagulation). During TURP and ThuP, normal saline was used as the flushing fluid during surgery. A $22 \mathrm{Fr}$ urethral triple-lumen Foley catheter was placed for traction for 8 hour post-operation and for continuous irrigation with sterile saline for 24 hours post-operation. The Foley was removed in 48-72 hours postoperatively. Antibiotic prophylaxis with first generation cephalosporin was administered pre-operatively and 12 hours post-operatively. Patients were then prescribed oral first-generation cephalosporin for a week.

We reviewed patient medical records to obtain the preoperative prostate specific antigen (PSA) level, complete hemochemical data (including white blood cell count, red blood cell count, platelet count, renal and liver function, and electrolytes), prostate volume (measured by transrectal ultrasound), pathology, operative times, uroflowmetry, comorbidities (hypertension, diabetes mellitus, coronary artery disease, 
cerebrovascular accident and chronic kideney disease) and the whether or not a Foley was inserted before surgery. The percentage of prostate resection was defined as the prostate specimen weight/prostate volume. Resection speed was defined as prostate specimen/operation time ( $\mathrm{g} / \mathrm{minutes})$. Chronic kidney disease was defined as an eGFR $<60 \mathrm{ml} / \mathrm{min} / 1.73 \mathrm{~m}^{2}$ or creatinine $>1.2 \mathrm{mg} / \mathrm{dl}$. All data were compared using Student's t-tests and chi-squared tests by IBM SPSS Statistics 25.0. Statistical significance was set at $p<0.05$.

Use of the data in the current study was approved by the Institutional Review Board of Mackay Memorial Hospital. All personal information was de-identified prior to data analysis, thus ensuring patient confidentiality.

\section{Results}

Our study showed that 66 patients developed BNC between 2008 and 2020. The incidence of BNC was $1.5 \%(35 / 2,363)$ after TURP and $1.6 \%(27 / 1,656)$ after ThuP. The average time to a diagnosis of BNC was 21.3 months (range from 2 to 130 months).

Sixty-two BNC patients with complete data (35 TURP and 27 ThuP) were randomly age-and operationmatched in a 1:2 ratio with 124 patients without BNC (70 TURP and 54 ThuP). The average age of BNC group and NBNC group was 70.2 and 69.7 years old respectively. ( $p$ values $>0.05$ ) (Table 1 )

Univariate and multivariate analysis showed that when compared with patients without BNC, those with BNC had significantly smaller prostates $(43.0 \pm 18.95 \mathrm{ml}$ vs $57.2 \pm 19.84 \mathrm{ml})$, lower resection weight ( $11.64 \pm 11.75 \mathrm{~g}$ vs $16.67 \pm 12.84 \mathrm{~g}$ ), shorter operative times ( $43.0 \pm 30.9 \mathrm{~min}$ vs $57.2 \pm 34.5 \mathrm{~min}$ ), and slower resection speed $(0.124 \pm 0.081 \mathrm{~g} / \mathrm{min}$ vs $0.151 \pm 0.952 \mathrm{~g} / \mathrm{min}$ ) (All $\mathrm{p}$ values $<0.05$ ). (Tables 1 and 2 ) There were no significant differences in percentage of prostate resected, initial PSA, maximal flow rate, and whether or not a Foley was inserted preoperatively.

Analysis of comorbidities showed that a greater proportion of BNC patients had history of cerebrovascular accidents (11/62 vs $7 / 124, p=0.009$, odds ratio:3.6), coronary artery disease( $14 / 48$ vs 16/108, $p=0.03$, odds ratio:2.0), chronic kidney disease (14/62 vs 11/124, $p=0.01$, odds ratio:3.0), and two or more comorbidities (29/62 vs 27/124, $p=0.001$, odds ratio:3.2). (Table 3 ) A ROC curve predicted that a prostate volume $<42.9 \mathrm{~cm}^{3}$ (AUC:0.718, sensitivity: 0.766 , specificity: 0.409 )had a higher rate of BNC (Figure 1).

\section{Discussion}

$\mathrm{BPH}$ with lower urinary tract symptoms is a common problem in older males. TURP is still considered the gold standard surgical treatment, and ThuP and Holmium laser enucleation of prostate (Holep) have recently been incorporated into national and international guidelines due to their noninferior efficacy and safety. ${ }^{8}$ BNC is a common postoperative complication that typically occurs early within the first 2 years 
post-operation. ${ }^{9}$ A meta-analysis reported that the incidence of BNC was $2 \% .{ }^{10}$ Another study showed that TURP resulted in BNC rates between $1 \%$ and $12.3 \%{ }^{2}$ The incidence of BNC reported after ThuP ranges from 0 to $2.4 \% .{ }^{11-13}$ The incidence of BNC after Holep is between 1.3 and 2.1\%. ${ }^{14-16}$ Our study results were comparable with these previous studies as the incidence of BNC was $1.5 \%$ after TURP and $1.6 \%$ after ThuP. No significant difference was observed in the incidence of BNC between TURP and ThuP.

BNC after prostate surgery is a well-known complication but its underlying cause is not well understood. Many risk factors, including small prostate volume, higher International Prostate Symptom Score storage scores, preoperative uncontrolled infection, unsuitable resectoscope, large resection loop, extensive resection of the bladder neck, long operative time and postoperative Foley insertion have been shown to be associated with the risk of BNC. 7,9 The most reported risk factor is small prostate volume with overresection of the bladder neck. Over-resection of the bladder neck can lead to fibrosis or scarring of the bladder neck, which in turn leads to BNC. Chiu et a/ reported that the incidence of BNC increased to $16 \%$ in patients with a prostate volume $<20 \mathrm{~g} .{ }^{17}$ Our study showed that a prostate volume $<42.9 \mathrm{~cm}^{3}$ had a higher rate of BNC. Qian et al. reported thulium laser enucleation significantly reduce the risk of BNC in small prostate less than $30 \mathrm{~g}$ due to no thermal injury to the bladder neck. ${ }^{18}$ The present study showed that small prostate volume, low weight of prostate resected, short operative time and low resection speed are risk factors for BNC. Low volume of prostate resected and short operative time were positively correlated with small prostate volume. Resection speed is a better parameter as it adjusts for resected prostate weight and operative time. Slow resection speed was correlated with unfavorable surgical processes, such as hemorrhage, poor endoscopic vision, prolonged operative time and perforation of the prostatic fossa or bladder neck. In these cases, more meticulate and extensive hemostasis using a bipolar resection loop or thulium laser fiber will likely be performed and this can lead to a higher chance of thermal injury of the bladder neck, which increases the risk of bladder neck scarring.

We hypothesized that preoperative comorbidities are potential risk factors for BNC. Microvascular disease may be associated with BNC due to poor healing and local ischemia. ${ }^{19}$ Development of microvascular disease, such as diabetes mellitus, coronary artery disease, cerebrovascular disease, hypertension and chronic kidney disease could theoretically alter the microvascular blood supply in the bladder neck, and accompanied by local ischemia and the wounds caused by TURP or ThuP, could lead to scar formation. In the current study, chronic kidney disease $(p<0.05)$, coronary artery disease $(p<0.05)$ and cerebrovascular accidents $(p<0.05)$ were associated with increasead BNC risk. In addition, the presence of $\geq 2$ comorbidities was a significant risk factor $(p<0.05)$ and 3.2 for $B N C$, which could indicate that there is a correlation between microvascular disease and BNC.

A prophylactic incision of the bladder neck using a bipolar loop or laser at the end of surgery, may reduce the incidence of BNC. ${ }^{7}$ Incision of the bladder neck by laser is preferred. ${ }^{20}$ Dysuria is the primary symptom of BNC, and a positive diagnosis is confirmed by cystoscopy. Urethral dilation is a potential management tool for BNC but repeat urethral dilation due to recurrent BNC was observed in $90 \%$ of patients in the first two years. ${ }^{21} \mathrm{BNC}$ is managed by bladder neck incision, which has a $72 \%$ success rate. 
22 In our study, 62 patients with BNC received bladder neck incision via bipolar instruments and there was no recurrence of BNC. Refractory BNC presents as recurrent dysuria in a short time and may require repeat bladder neck incision. Another technique combines bladder neck incision with a transurethral irrigation agent or transurethral injection of a cytotoxic agent. Eltahawy et al. reported an $83 \%$ success rate for the combination of bladder neck incision via Holmium laser and irrigation with triamcinolone, while Redshaw et al. showed a 75\% success rate for bladder neck incision using a cold-knife and transurethral injection of mitomycin C. ${ }^{23,24}$

This study had several limitations. First, we did not use the International Prostate Symptom Score as a parameter in the study due to incomplete medical records. Preoperative Foley status and maximal flow rates were not significant different between the BNC and NBNC patients ( $p>0.05)$. Second, it was a single center, retrospective study, the number of patients was small and selection bias would be existent. Third, some patients were lost to follow-up years after TURP or ThuP, which could lead to an underestimation of the BNC incidence rates. There were the same size of resectoscope, resection loop and energy settings, no previous endourological interventions and all patients were age-and operation-matched, all of which minimized bias in the present study.

Our study demonstrated that the incidence was the same in TUPR and ThuP and low prostate volume, low resection speed and the presence of $\geq 2$ comorbidities were positively correlated with the development of BNC after TURP or ThuP. A small prostate volume less than $<42.9 \mathrm{~cm}^{3}$ had a higher rate of BNC. However, larger studies are needed to verify these results. Our study may serve as reference for clinical urologists and our results can be used during the explanation of BNC risks before surgery.

\section{List Of Abbreviations}

PSA: Prostate Specific Antigen

BPH: Benign prostate hyperplasia

TURP: bipolar Transurethral resection of prostate

ThuP: thulium vaporesection/vapoenucleation/enucleation of the prostate

BNC: bladder neck contracture

Holep: Holmium laser enucleation of prostate

\section{Declaration}

\section{Ethics approval and consent to participate}

The present study, including its research protocols and data collection, were approved by the Institutional Review Board of Mackay Memorial Hospital. In view of the retrospective nature of the study, obtaining 
patients' informed consent was waived.

\section{Consent for publication}

Not applicable

\section{Availability of data and material}

Records and data pertaining to this study are in the patient's secure medical records in Mackay Memorial Hospital and are available from the corresponding author on reasonable request. All methods were performed in accordance with the relevant guidelines and regulations and approved by the Institutional Review Board of Mackay Memorial Hospital.

\section{Competing interests}

The authors declare that they have no competing interests.

\section{Fundings}

None to declare.

\section{Authors' contributions}

YZC: project development, data collection, data analysis, and manuscript writing. WRL: data collection and data analysis. YCC: data collection and data analysis. WKT: data collection and data analysis. MC: project development, data analysis, and manuscript editing. AWC: manuscript editing.

All authors have read and approved the manuscript.

\section{Conflict of interests:}

There are no conflicts of interest.

\section{Acknowledgements:}

There is no potential financial and non-financial funding.

\section{References}

1. Cindolo L, Marchioni M, Emiliani E, et al. Bladder neck contracture after surgery for benign prostatic obstruction. Minerva Urol Nefrol. 2017;69(2):133-143.

2. Rassweiler J, Teber D, Kuntz R, Hofmann R. Complications of transurethral resection of the prostate (TURP)-incidence, management, and prevention. Eur Urol. 2006;50(5):969-979; discussion 980.

3. Lin Y, Wu X, Xu A, et al. Transurethral enucleation of the prostate versus transvesical open prostatectomy for large benign prostatic hyperplasia: a systematic review and meta-analysis of 
randomized controlled trials. World J Urol. 2016;34(9):1207-1219.

4. Lee YH, Chiu AW, Huang JK. Comprehensive study of bladder neck contracture after transurethral resection of prostate. Urology. 2005;65(3):498-503; discussion 503.

5. Doluoglu OG, Gokkaya CS, Aktas BK, et al. Impact of asymptomatic prostatitis on re-operations due to urethral stricture or bladder neck contracture developed after TUR-P. Int Urol Nephrol. 2012;44(4):1085-1090.

6. Grechenkov A, Sukhanov R, Bezrukov E, et al. Risk factors for urethral stricture and/or bladder neck contracture after monopolar transurethral resection of the prostate for benign prostatic hyperplasia. Urologia. 2018;85(4):150-157.

7. Tao H, Jiang YY, Jun Q, et al. Analysis of risk factors leading to postoperative urethral stricture and bladder neck contracture following transurethral resection of prostate. Int Braz J Urol. 2016;42(2):302-311.

8. Gravas S. CJN, Gacci M., Gratzke C., Herrmann T.R.W., Mamoulakis C., Rieken M., Speakman M.J., Tikkinen K.A.O. Management of Non-neurogenic Male LUTS. 2020; https://uroweb.org/guideline/treatment-of-non-neurogenic-male-luts/ - 1_3.

9. Young BW. The retropubic approach to vesical neck obstruction in children. Surg Gynecol Obstet. 1953;96(2):150-154.

10. Ahyai SA, Gilling P, Kaplan SA, et al. Meta-analysis of functional outcomes and complications following transurethral procedures for lower urinary tract symptoms resulting from benign prostatic enlargement. Eur Urol. 2010;58(3):384-397.

11. Netsch C, Bach T, Herrmann TR, Gross AJ. Thulium:YAG VapoEnucleation of the prostate in large glands: a prospective comparison using 70- and 120-W 2-microm lasers. Asian J Androl. 2012;14(2):325-329.

12. Netsch C, Pohlmann L, Herrmann TR, Gross AJ, Bach T. 120-W 2-microm thulium:yttrium-aluminiumgarnet vapoenucleation of the prostate: 12-month follow-up. BJU Int. 2012;110(1):96-101.

13. Elshal AM, Elmansy HM, Elhilali MM. Two laser ablation techniques for a prostate less than $60 \mathrm{~mL}$ : lessons learned 70 months after a randomized controlled trial. Urology. 2013;82(2):416-422.

14. Primiceri G, Castellan P, Marchioni M, Schips L, Cindolo L. Bladder Neck Contracture After Endoscopic Surgery for Benign Prostatic Obstruction: Incidence, Treatment, and Outcomes. Curr Urol Rep. 2017;18(10):79.

15. Ibrahim A, Alharbi M, Elhilali MM, Aube M, Carrier S. 18 Years of Holmium Laser Enucleation of the Prostate: A Single Center Experience. J Urol. 2019;202(4):795-800.

16. Elzayat EA, Elhilali MM. Holmium laser enucleation of the prostate (HoLEP): long-term results, reoperation rate, and possible impact of the learning curve. Eur Urol. 2007;52(5):1465-1471.

17. Chiu AW, Chen MT, Chang LS, et al. Prophylactic bladder neck incision in the treatment of small benign prostatic hyperplasia. Zhonghua Yi Xue Za Zhi (Taipei). 1990;45(1):22-25. 
18. Sun Q, Guo W, Cui D, et al. Thulium laser enucleation versus thulium laser resection of the prostate for prevention of bladder neck contracture in a small prostate: a prospective randomized trial. World J Urol. 2019;37(5):853-859.

19. Borboroglu PG, Sands JP, Roberts JL, Amling CL. Risk factors for vesicourethral anastomotic stricture after radical prostatectomy. Urology. 2000;56(1):96-100.

20. Madersbacher S, Marberger M. Is transurethral resection of the prostate still justified? BJU Int. 1999;83(3):227-237.

21. Kaynar M, Gul M, Kucur M, Celik E, Bugday MS, Goktas S. Necessity of routine histopathological evaluation subsequent to bladder neck contracture resection. Cent European J Urol. 2016;69(4):353357.

22. Herschorn S, Elliott S, Coburn M, Wessells H, Zinman L. SIU/ICUD Consultation on Urethral Strictures: Posterior urethral stenosis after treatment of prostate cancer. Urology. 2014;83(3 Suppl):S59-70.

23. Altay B, Erkurt B, Kiremit MC, Guzelburc V, Boz MY, Albayrak S. 180-W XPS GreenLight laser vaporization for benign prostate hyperplasia: 12-month safety and efficacy results for glands larger than $80 \mathrm{~mL}$. Lasers Med Sci. 2015;30(1):317-323.

24. Guo S, Muller G, Lehmann K, et al. The 80-W KTP GreenLight laser vaporization of the prostate versus transurethral resection of the prostate (TURP): adjusted analysis of 5-year results of a prospective non-randomized bi-center study. Lasers Med Sci. 2015;30(3):1147-1151.

\section{Tables}

Table 1. Univariate analysis between the BNC and NBNC groups.

\begin{tabular}{|llll|}
\hline & BNC (N=62) & NBNC (N=124) & P-value \\
\hline Age (years) & 70.26 & 69.67 & 0.746 \\
\hline Prostate volume (ml) & $43.0 \pm 18.95$ & $57.2 \pm 19.84$ & $0.001^{\star \star}$ \\
\hline Prostate resection weight (g) & $11.64 \pm 11.75$ & $16.67 \pm 12.84$ & $0.001^{\star \star}$ \\
\hline Percentage of prostate resected (\%) & $27.2 \pm 19.36$ & $27.5 \pm 15.13$ & 0.91 \\
\hline Operative time (minutes) & $43.0 \pm 30.9$ & $57.2 \pm 34.5$ & $0.001^{\star \star}$ \\
\hline Resection speed (g/min) & $0.124 \pm 0.081$ & $0.151 \pm 0.952$ & $0.048^{\star \star}$ \\
\hline PSA (ng/ml) & $8.04 \pm 16.19$ & $9.0 \pm 14.02$ & 0.674 \\
\hline Maximal urinary flow (ml/sec) & $10.4 \pm 8.84$ & $8.28 \pm 5.94$ & 0.055 \\
\hline Foley insertion before TURP or ThuP & & & 0.431 \\
\hline Yes & 14 & 22 & \\
\hline No & 48 & 102 & \\
\hline
\end{tabular}


Table 2. Multivariate analyses between the BNC and NBNC groups.

\begin{tabular}{|llll|}
\hline & BNC $(\mathrm{N}=62)$ & NBNC $(\mathrm{N}=124)$ & P-value \\
\hline Prostate volume $(\mathrm{ml})$ & $43.0 \pm 18.95$ & $57.2 \pm 19.84$ & $0.000^{* *}$ \\
\hline Prostate resection weight $(\mathrm{g})$ & $11.64 \pm 11.75$ & $16.67 \pm 12.84$ & $0.009 * *$ \\
\hline Percentage of prostate resected $(\%)$ & $27.2 \pm 19.36$ & $27.5 \pm 15.13$ & 0.912 \\
\hline Operative time (minutes) & $43.0 \pm 30.9$ & $57.2 \pm 34.5$ & $0.000^{* *}$ \\
\hline Resection speed $(\mathrm{g} / \mathrm{min})$ & $0.124 \pm 0.081$ & $0.151 \pm 0.952$ & $0.041 * *$ \\
\hline PSA (ng/ml) & $8.04 \pm 16.19$ & $9.0 \pm 14.02$ & 0.694 \\
\hline Maximal urinary flow $(\mathrm{ml} / \mathrm{sec})$ & $10.4 \pm 8.84$ & $8.28 \pm 5.94$ & 0.052 \\
\hline
\end{tabular}

Table 3. Comorbidity analyses between the BNC and NBNC groups.

\begin{tabular}{|c|c|c|c|c|}
\hline All (yes/no) & $\begin{array}{l}\text { BNC } \\
(\mathrm{N}=62)\end{array}$ & $\begin{array}{l}\text { NBNC } \\
(\mathrm{N}=124)\end{array}$ & $\begin{array}{l}\text { P-valu } P \\
\text { value }\end{array}$ & $\begin{array}{l}\mathrm{OO} \otimes \\
\text { ratio Odds } \\
\text { (95\% interval) }\end{array}$ \\
\hline Hypertension (yes/no) & $35 / 27$ & $56 / 68$ & 0.146 & $1.6(0.9-2.9)$ \\
\hline Diabetes mellitus (yes/no) & $14 / 48$ & $18 / 106$ & 0.17 & $1.7(0.8-3.7)$ \\
\hline $\begin{array}{l}\text { Cerebrovascular accidents } \\
\text { (yes/no) }\end{array}$ & $11 / 51$ & $7 / 117$ & $0.009 * \star$ & $3.6^{* *}(1.3-9.8)$ \\
\hline Coronary artery disease (yes/no) & $14 / 48$ & $16 / 108$ & $0.03^{\star \star}$ & $2.0 * *(0.9-4.4)$ \\
\hline Chronic kidney disease(yes/no) & $14 / 48$ & $11 / 113$ & $0.01 * *$ & $3.0 * *(1.2-7.0)$ \\
\hline $\begin{array}{l}\text { Number of Comorbidities }(\geq 2 / \\
\leq 1)\end{array}$ & $29 / 33$ & $27 / 97$ & $0.001 * *$ & $3.2^{\star *}(1.6-6.1)$ \\
\hline Prostate cancer (yes/no) & $8 / 54$ & $10 / 114$ & 0.293 & $1.7(0.6-4.5)$ \\
\hline Other malignancy (yes/no) & $6 / 56$ & $4 / 54$ & 0.086 & 3.2(0.9-11.8) \\
\hline
\end{tabular}

\section{Figures}




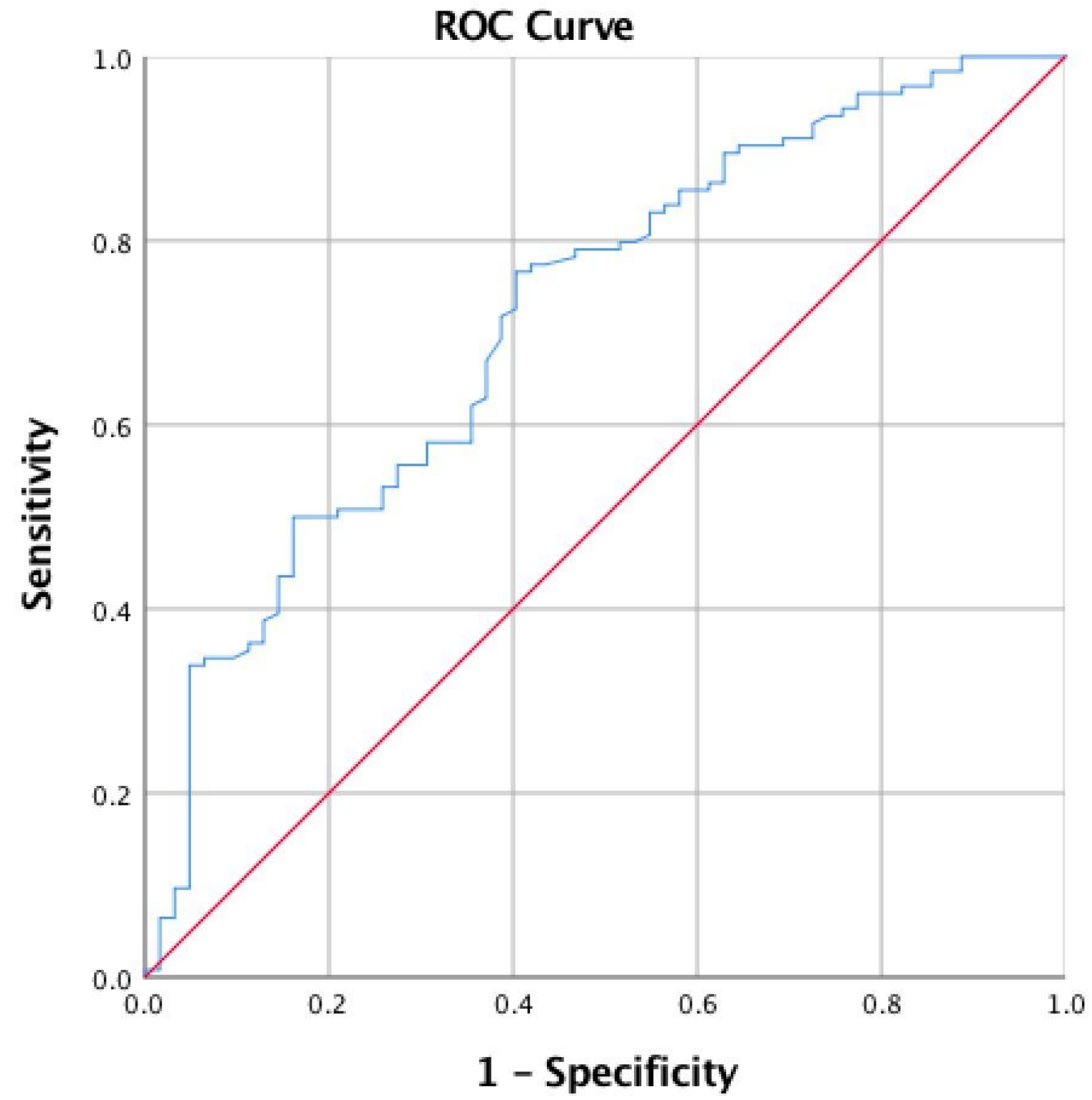

Figure 1

ROC curve for prostate volume to determine the cutoff value that predicts the occurrence of BNC after TURP or ThuP. Note: red line, reference line; blue line, prostate volume in $\mathrm{cm} 3$. Threshold: prostate volume: $42.9 \mathrm{~cm} 3$, AUC:0.718, sensitivity: 0.766 , specificity: 0.409 